\title{
Optimized Design of Precision EDM Machine Tool based on CAE Simulation and Modal Testing Technology
}

\author{
Jianyong Liu ${ }^{1 *}$, Yanhua Cai ${ }^{1}$, Haifeng Zhang ${ }^{2}$ and Liantong Ding ${ }^{1}$ \\ ${ }^{1}$ Beijing Institute of Electro-Machining, Beijing 100191, China \\ ${ }^{2}$ Inverter Technologies Engineering Research Center of Beijing, North China University of Technology, Beijing, 100144, China
}

\begin{abstract}
For precision EDM equipment, in addition to the static stiffness of the body of the machine, the dynamic characteristics of the body and the ambient temperature are also the key factors that affect the machining accuracy of the workpieces. In this paper, through the modal simulation analysis of the machine tool that with the sheet metal shell, the weak points of the EDM machine tool are determined. Through thermal stress simulation analysis, the thermal deformation law of the workpieces mounting table is determined, and a solution to reduce thermal deformation is proposed. Through machine tool ODS (operating deflection shapes) test and analysis, the weak links of the machine tool's body in actual processing are determined. Through the above optimization analysis, the foundation has been laid for improving the dynamic and static accuracy of the precision machine tool. The research method in this paper makes up for the deficiency of the machine tool design method based on static stiffness.
\end{abstract}

tools.

\section{Introduction}

With the rapid development of key fields such as aviation, aerospace, automotive, energy, the requirements for mechanical performance and machining accuracy of workpieces are getting higher and higher[1].This puts forward higher requirements on the mechanical dynamic and static accuracy of its corresponding processing equipment. Precision EDM equipment is the key equipment indispensable for the processing of key equipment's important parts in the fields of aviation, aerospace, automobile, energy and other fields [2-4], such as integral blisks, high pressure common rail injectors, aviation blades, and so on. .At present, in the development process of the main engine of EDM equipment, only by improving the static stiffness of the machine tool to improve the machining accuracy of the equipment, it has been unable to meet the machining needs of highprecision parts. For the processing of high-precision parts, the dynamic characteristics of the machinetool and changes in ambient temperature are also key factors affecting the final machining accuracy of the parts. In this paper, model simulation analysis, thermal-stress deformation analysis and operating deflection shapes (ODS) testing based on actual working conditions will be carried out on the main body of typical precision C-typed EDM machine tools. Based on the these research, the influence of the weak points of the precision machine tool and the influence of ambient temperature on the deformation of the parts installation table are determined. The research results will provide theoretical support for the advancement and optimization of precision machine

\section{Modal simulation and test analysis of the EDM machine tool}

For a C-typed EDM machine tool, the main body includes castings such as the machine bed, column, and middle slide, as well as auxiliary sheet metal parts. For the analysis of the dynamic characteristics of precision machine tools, the influence of the dynamic characteristics of the machine tool sheet metal shell on the performance of the machine tool cannot be eliminated. Therefore, this section carries out a simulation analysis on the main body of the machine tool model including the sheet metal shell. Among them, the casting material is HT250, and the sheet metal shell material is Q235.

In order to carry out CAE simulation analysis, first, mesh the three-dimensional digital model of the machine tool. When meshing, most of the thin-walled construction is simplified into a midplane. Under the premise of ensuring the validity of the calculation results, other structures that do not have thin-wall features are appropriately optimized. When meshing, use a twodimensional hybrid mesh to divide the two-dimensional geometry, and use a structured hexahedral mesh to divide the solid geometry. The mesh model of the main machine body after the mesh is divided is shown in Figure1, and Figure 2 shows the local mesh diagram of the main machine body. The restraint state of the machine tool is to fix and restrain its anchor bolts under the normal arrangement state.

In the vibration analysis, the micro-vibration equation of the linear system near the stable equilibrium position is: 


$$
\mathrm{M} \ddot{q}+\mathrm{Cq}+\mathrm{Kq}=\mathrm{Q}
$$

Where, $\mathrm{M}, \mathrm{C}$ and $\mathrm{K}$ are the mass, damping and stiffness matrixs of the system respectively, and Q is the generalized disturbance force array.

The essence of modal analysis is to solve the modal vector of the motion equation with finite degrees of freedom while ignoring the external force and damping, so equation (1) can be simplified as:

$$
\mathrm{Mq}+\mathrm{Kq}=0
$$

Set $\mathrm{K}$ and $\mathrm{M}$ as constants, and use the CAE software

Figure 1. Meshing model of the main bodyof the EDM machine tool.

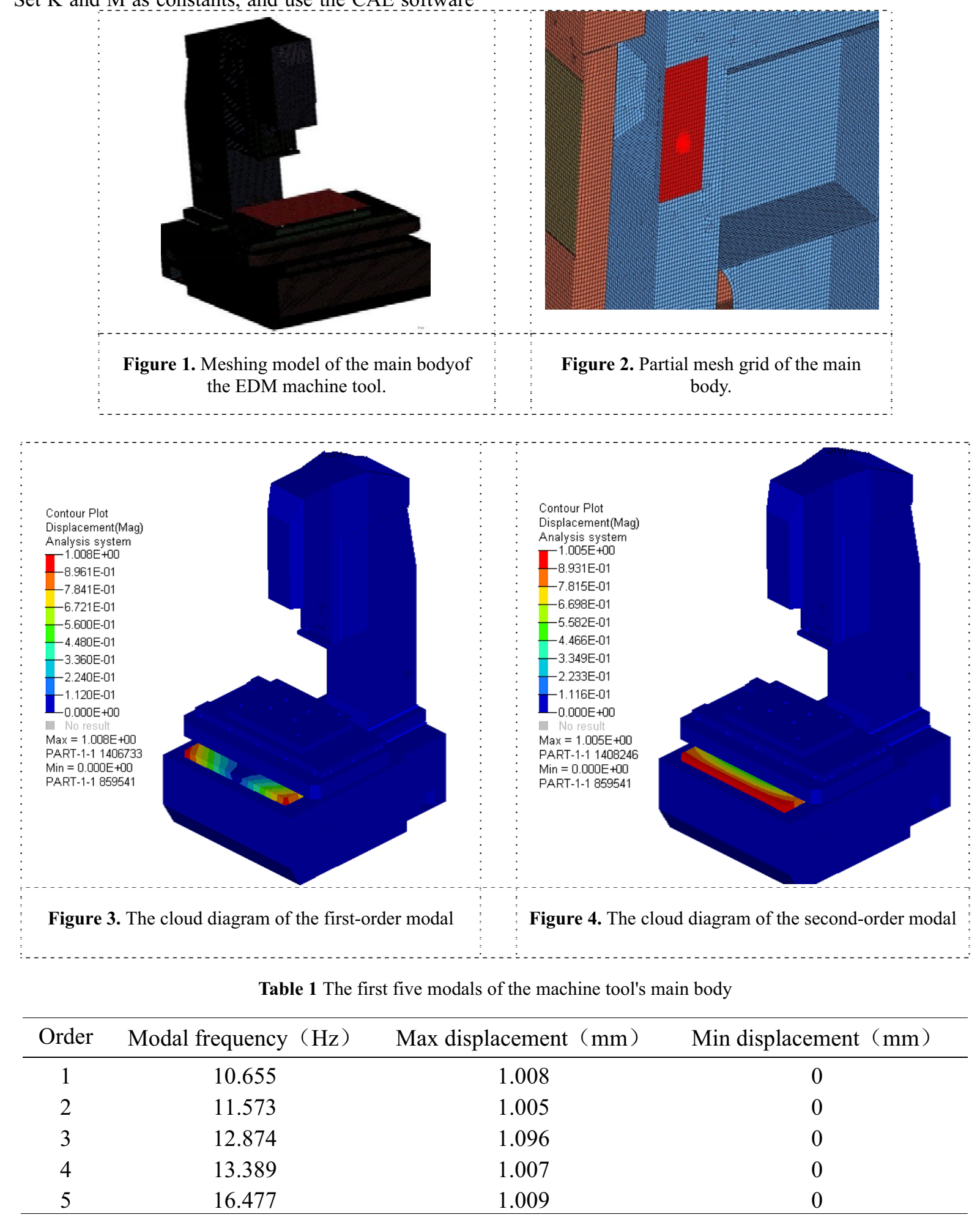

to analysis the modal of the machine tool[5-7]. The first five-order machine modals obtained through modal simulation analysis are shown in Table 1. Figure 3 and Figure 4 are the first-order and second-order formation cloud diagrams respectively.

From the modal simulation results, it can be seen that the sheet metal installation support of the machine tool is relatively weak, and it is easier to produce chatter during processing. 


\section{Thermal Stress and Deformation Simulation of Workpiece Mounting Table}

For precision machine tools, changes in ambient temperature have a great impact on the structural accuracy of key parts of the machine tool[8,9]. For EDM machine tools, different from general machining machine tools, in many cases the part mounting table is made of granite and the fixed base surface is made of cast iron. Therefore, when the ambient temperature changes, the flatness of the workpiece mounting table will change due to the different thermal expansion coefficients of the materials. This will have a greater impact on the accuracy of the workpiece installation, and directly affect the machining accuracy of the processed parts.

The worktable of a typical EDM machine tool is made of granite, and the work table and the mounting base are connected by bolts. This section will analyze when the temperature rises from $20^{\circ} \mathrm{C}$ to $30^{\circ} \mathrm{C}$, the thermal stress distribution of the surface of the work table and the displacement changes caused by the different thermal expansion coefficients during the simulation temperature change process. And through the thermal stress simulation analysis, the general law of the flatness of the granite worktable changing with the temperature is obtained.

According to the mechanical properties of materials, the magnitude of thermal stress depends on the temperature gradient. When the temperature change value of the material is $\Delta \mathrm{T}$, the thermal stress value of the material can be calculated by the following formula:

$$
\sigma_{T}=\alpha E \Delta T
$$

Where, $\sigma \mathrm{T}$ is the thermal stress value $(\mathrm{MPa}), \alpha$ is the linear expansion coefficient of the material $(1.0 \mathrm{e}-6 / \mathrm{K})$, and $\mathrm{E}$ is the elastic modulus $(\mathrm{GPa})$ of the material.

In order to improve calculation efficiency, this section simplifies the model of the machine tool, and only simulates and only simulates and analyzes key components such as the bed, the workpiece mounting table and it's installation base. The structured hexahedral element model is used to replace the original solid model for calculation and analysis. On the premise of ensuring the calculation accuracy and improving the calculation efficiency, the size of the grid is reasonably controlled, and a total of 969,818 grid elements and 994,879 element nodes are obtained. The calculation model after meshing is shown in Figure 5.

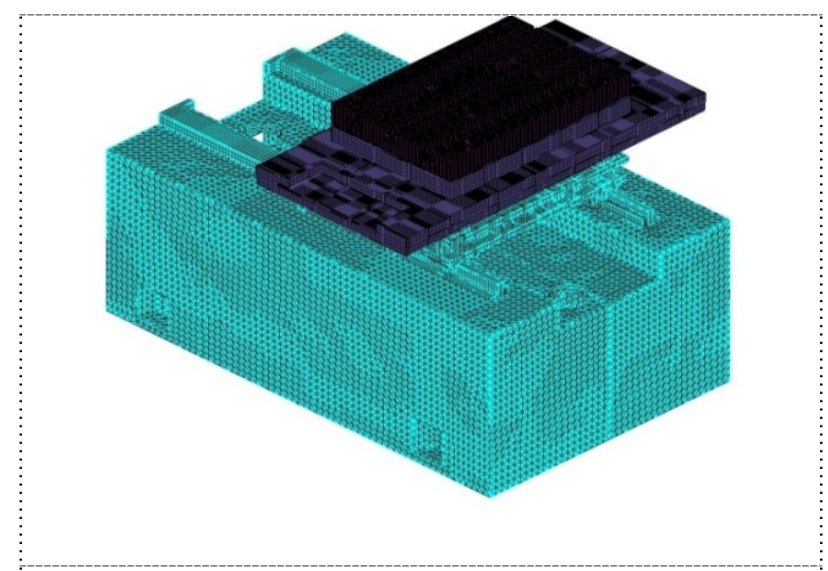

Figure 5. Grid model of the machine tool's components

The silmulation model contains two materials, granite and HT250.Set the initial condition of the model to $20^{\circ} \mathrm{C}$, and the final boundary condition to $30^{\circ} \mathrm{C}$. And the given acceleration of gravity is $9.8 \mathrm{~m} / \mathrm{s} 2$.Figure 6 is the stress cloud diagram of the calculated model when the ambient temperature rises from $20^{\circ} \mathrm{C}$ to $30^{\circ} \mathrm{C}$ obtained by simulation. Figure 7 shows the corresponding overall stress cloud diagram.

In order to describe the deformation of the workpiece mounting table more intuitively, Figure 8 and Figure 9 show the displacement curves of the long and short sides where the maximum displacement node on the workpiece mounting table is located. The node at $600 \mathrm{~mm}$ in Figure 8 is the maximum displacement node on the workpiece mounting table, and the maximum displacement node is located at $0 \mathrm{~mm}$ in Figure 9. There are obviously two jumps in the curve in Figure 9, because the displacement values of the nodes on the two sides of the left and right grooves on the workpiece mounting table are quite different.

It can be seen from the simulation results that the maximum thermal deformation appears on the machine bed, and its value is $0.095 \mathrm{~mm}$. The maximum thermal deformation of the workpiece mounting table is $0.087 \mathrm{~mm}$ at the corners. In the process of increasing the ambient temperature from $20^{\circ} \mathrm{C}$ to $30^{\circ} \mathrm{C}$, due to the large difference in thermal expansion coefficient between HT250 and granite, the deformation speed and degree of the two materials are very different. During the thermal deformation of the material, the bolts connecting the two materials are mainly subjected to shear stress. If the bolt diameter is increased, the stress value at the bolt connection can be effectively reduced. 

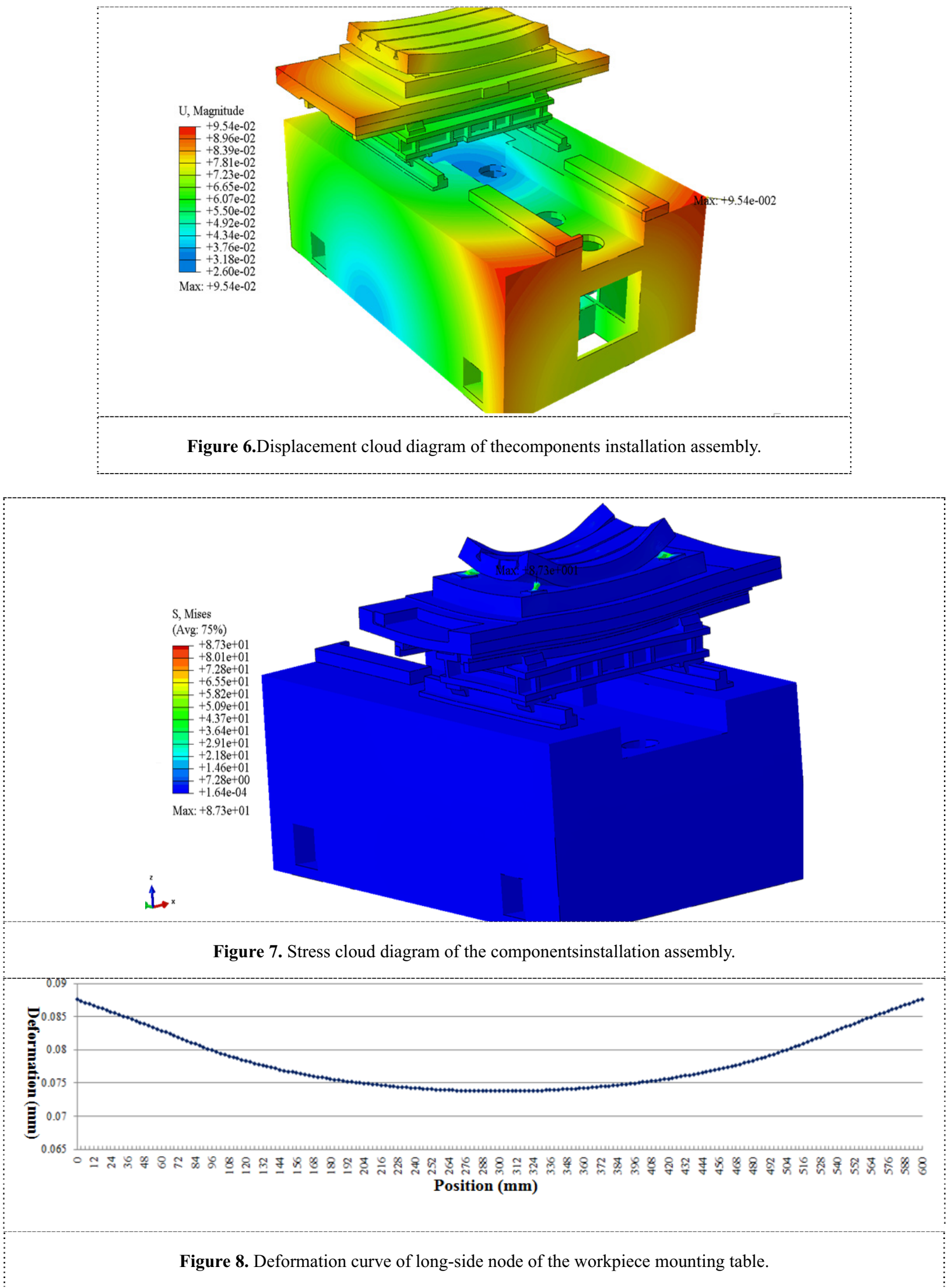


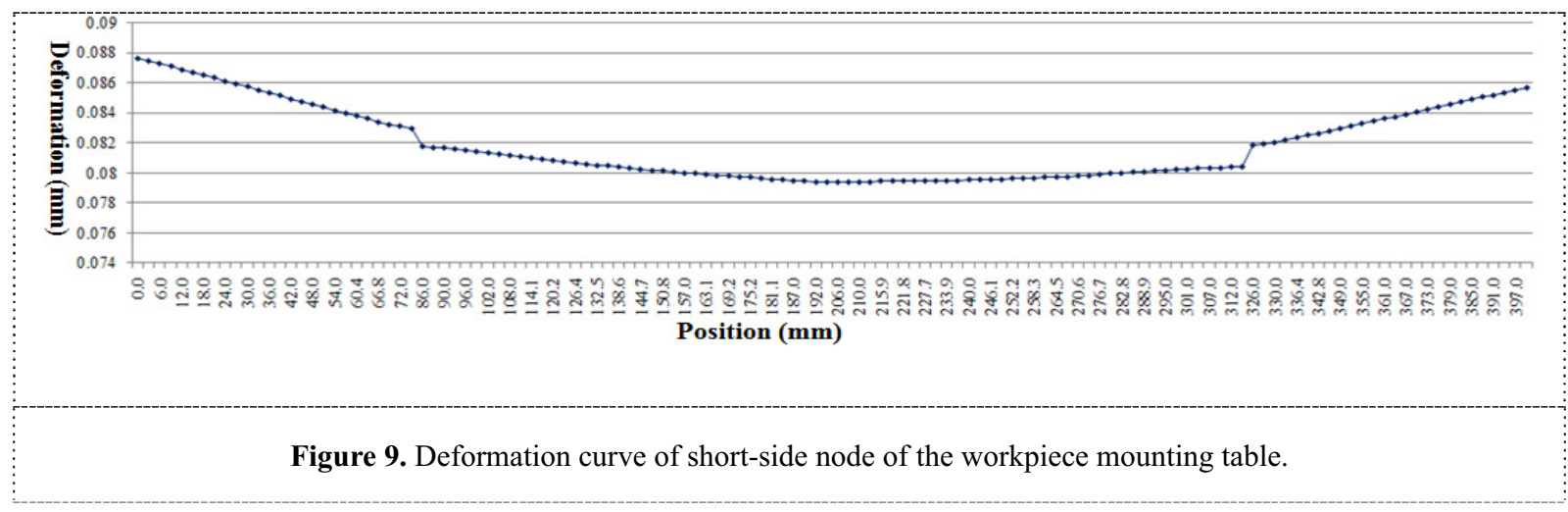

\section{Test and analysis the ODS of the machine tool}

The ODS (operating deflection shapes) test is defined as the analysis of the vibration and deformation of the structure at a certain frequency, indicating the vibration state of the structure under a certain working state. The specific test method is to fix a certain sensor at a certain position, and the other sensors move on key structural points to obtain signals[10,11]. The signal of the fixed sensor is the excitation signal, and the other signals are the response signals. Base on these signals, the frequency response function when the system is in working state can be obtained. The ODS analysis method can provide the main vibration source and noise source of the entire machine tool structure, and is used to solve problems such as structural resonance and fatigue.
The equipment used in this experiment is the modal test analysis system of Danish B\&K Company. The main test equipment includes: three-direction acceleration sensor, pulse system, 3560B data acquisition front end, and so on. Import the measured frequency response function data into ME'scopeVES software, and perform modal parameter identification in the software. Due to the limited number of sensors, each test is carried out twice. The sensor signal at the lower end of the $\mathrm{Z}$ axis is set as the reference signal (excitation signal), and the other sensor positions are moved until all measuring points are measured. The machine tool to be tested is shown in Figure 10. Establish models according to the different postures of the machine tool, insert sensors into the model, and adjust the orientation and position of the sensors. And measure the ODS in the $\mathrm{X}, \mathrm{Y}$, and $\mathrm{Z}$ directions when the machine is in the middle position. Test the modal under different postures of the machine tool, and the test interface is shown in Figure 11.

Figure 10. Machine tool in ODS test.



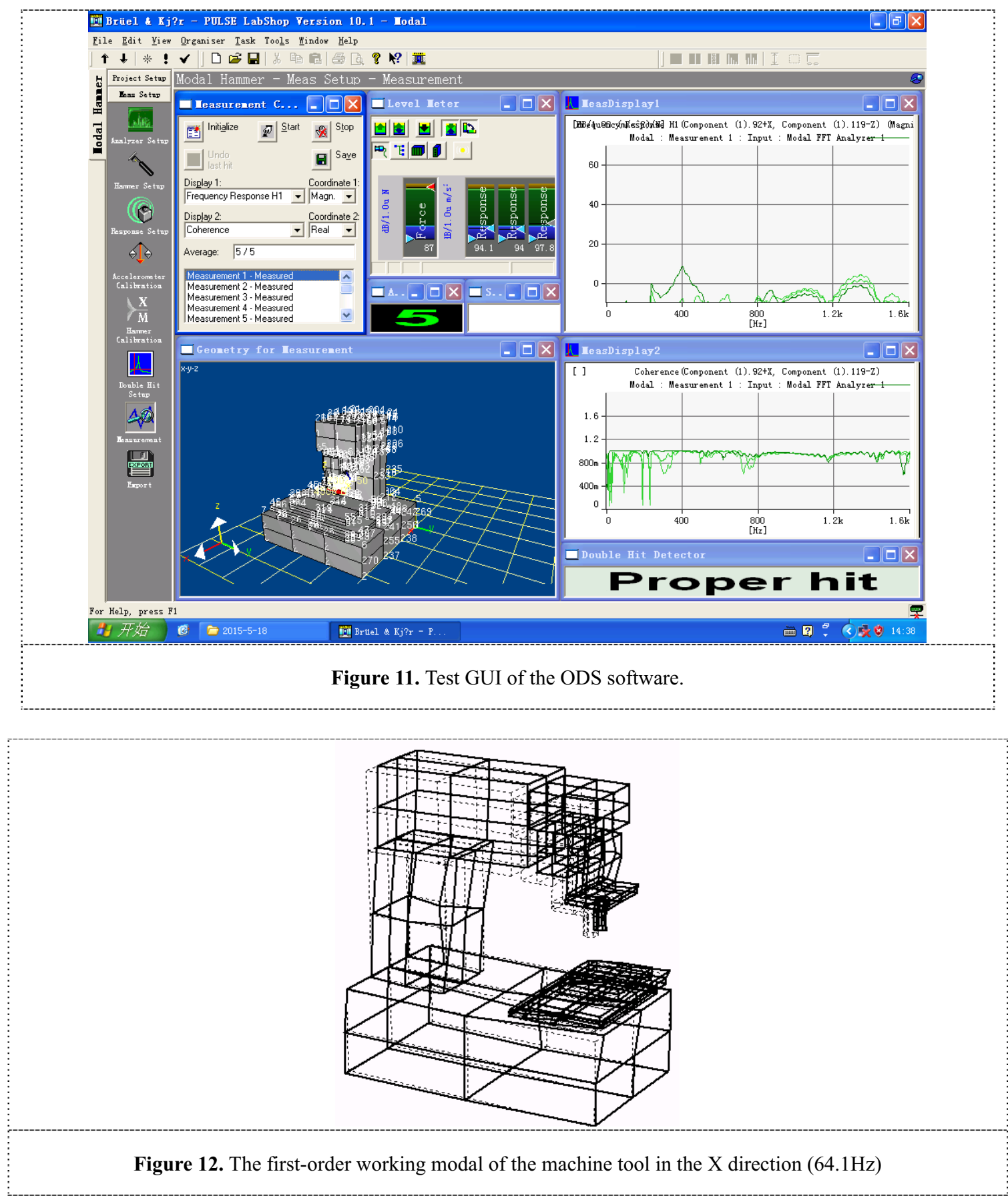

Taking the machining state when the $\mathrm{X}$ and $\mathrm{Y}$ axes of the machine tool are both in the middle position as an example, the operating frequencies of each order in the $\mathrm{X}$, $\mathrm{Y}$, and $\mathrm{Z}$ directions are shown in Table 2. Figure.12 shows the first-order work formation of the machine tool when the sensor is arranged in the $\mathrm{X}$ direction.
Through ODS test and analysis, it can be obtained that the rigidity of the bracket connecting the electrode is relatively weak, and the structure should be opti ized. When moving in the $\mathrm{Z}$ direction, the entire machine tool has obvious vibration in the $\mathrm{Y}$ direction, the machine tool has vibration, and the rigidity of the foot part is weak.

Table 2 The operating frequency of each order in the three directions of $\mathrm{X}, \mathrm{Y}$ and $\mathrm{Z}$

\begin{tabular}{ccc}
\hline Sensor direction & Modal Order & Modal frequency $(\mathrm{Hz})$ \\
\hline & 1 & 64.1 \\
X direction & 2 & 185 \\
& 3 & 375 \\
& 5 & 475 \\
Y direction & 1 & 560 \\
\hline
\end{tabular}




\begin{tabular}{lll}
\hline & 2 & 128 \\
3 & 185 \\
4 & 237 \\
5 & 300 \\
1 & 72 \\
2 & 2 & 329 \\
& 3 & 381 \\
& 4 & 488 \\
\hline
\end{tabular}

\section{Conclusions}

This article aims to optimize the performance of the EDM machine tool. Through the combination of machine tool modal simulation analysis, workpiece mounting table thermal-stress deformation simulation analysis, and operating deflection shapes (ODS)test, the weak points of the static and dynamic characteristics of the C-typed EDM machine tool are systematically analyzed, the main research work is as follows:

(1) Through finite element modal simulation, the first five modals of the C-typed EDM machine tool are extracted, and it is determined that the sheet metal installation support of the machine tool is relatively weak, and it is easier to produce chatter during machining.

(2) Through thermal-stress simulation analysis, the thermal stress and deformation characteristics of the workpiece mounting table were studied, and the thermal deformation law of the workpiece mounting table of was given.

(3) Establish models according to the different postures of the machine tool, insert sensors into the model, and adjust the orientation and position of the sensors. And measure the ODS in the $\mathrm{X}, \mathrm{Y}$, and $\mathrm{Z}$ directions when the machine is in the middle position. And then determined the weak points of the EDM machine tool in the actual processing process.

Through the above optimization analysis, the machine tool is laid for further improving the dynamic and static accuracy of the precision EDM machine tool, which effectively makes up for the lack of the machine tool design method based only on the static stiffness characteristics of the machine tool.

\section{Acknowledgements}

This research was supported by 2018 Nova Program English (Z181100006218078)

\section{References}

1. Zhao Wansheng, Gu Lin, Kang Xiaoming, etal. Research Trends of International Non-traditional Machining_Roundup of ISEM XVII[J], Electromachining \& Mould, 2013(6):1-10.

2. Yang D Y, Cao F G, Liu J Y, et al. Overview on FiveAxis Precision EDM Techniques[J]. Prodedia CIRP, 2013, 6:192-198.
3. Lin Xiufeng. Discussion on Related Issues of Fiveaxis Linkage EDM Technology[J].Science and Technology Innovation Herald, 2014(21):88

4. UHLMANN E, DOMINGOS D C. Development and optimization of the die-sinking EDM-technology for machining the nickel-based alloy MAR-M247 for turbine components[J]. Procedia CIRP, 2013, 6: 180185.

5. ZHANG Xian dong, XU Yuan shen, LIN Han yuan.Static and dynamic design on structural components of NC machine tools based on FEM[J]. Journal of Machine Design, 2005, 22(5):46-48.

6. SUN Yongqing, WANG Yongquan, ZHU Xiang,etal. Analysis and Improvement of Machine Tool Dynamic Performance Based on ANSYS /WORKBENCH[J]. MACHINE TOOL \& HYDRAULICS, 2012, 040(001):110-113.

7. WANG Yuan-lun,LI Shao-ping, PENG Liangfeng,etal,Static and Dynamic Analysis on Beam Parts of Bridge Gantry Boring and MillingMachine[J]. Construction \& Design for Engineering, 2016, 000(015):90-92.

8. Mounir Muhammad Koura, Muhammad Lotfy Zamzam, Amr Ahmed Sayed Shaaban. Simulation Approach to Evaluate the Thermal Behavior of A 3Axis Milling Machine Based on FEM[J]. Esrsa Publications, 2014.

9. Zaeh, Michael Friedrich, Maier. Finite Element Analysis for Thermal Behavior[C]// Lunar \& Planetary Science Conference. Lunar and Planetary Science Conference, 2010.

10. Bai Xianghe. Optimal Placement of Excitations and Sensors For CNC Machine Tools[D].Huazhong University of Science and Technology,2012.

11. WANG Min,N IU Huanhuan, GAO Xiangsheng, WANG Minda.Modal Analysis and Vibration Reduction Design on an EDM Machine Tool Spindle, 2017, 37(005):905-909. 